\title{
ErMiao San Inhibits Angiogenesis in Rheumatoid Arthritis by Suppressing JAK/STAT Signaling Pathways
}

\author{
Lianhua He, ${ }^{1,2}$ Qingxia Qin, ${ }^{2}$ Juan He, ${ }^{2}$ Han Wang, ${ }^{2}$ Yiping Hu, ${ }^{2}$ Wencheng He, ${ }^{1}$ Bihua Xu, ${ }^{2}$ \\ Gengmin Zhou, ${ }^{2}$ Hongying Shan, ${ }^{2}$ Bo Yang, ${ }^{2}$ and Qingwen Wang $\mathbb{D}^{2}$ \\ ${ }^{1}$ Department of Rheumatism and Immunology, Peking University Shenzhen Hospital, \\ Shenzhen Peking University-The Hong Kong University of Science and Technology Medical Center, Shenzhen 518036, China \\ ${ }^{2}$ Department of Rheumatism and Immunology, Peking University Shenzhen Hospital, Shenzhen 518036, China
}

Correspondence should be addressed to Qingwen Wang; wqw_sw@163.com

Received 30 October 2019; Revised 25 December 2019; Accepted 8 January 2020; Published 19 February 2020

Academic Editor: Francesca Mancianti

Copyright (c) 2020 Lianhua He et al. This is an open access article distributed under the Creative Commons Attribution License, which permits unrestricted use, distribution, and reproduction in any medium, provided the original work is properly cited.

ErMiao San (EMS) is composed of the Cortex Phellodendri chinensis and Atractylodes lancea, and it has the function of eliminating heat and excreting dampness in terms of traditional Chinese medicine to damp heat syndrome. Previous reports indicate that EMS possesses anti-inflammatory activity; however, its action on angiogenesis of rheumatoid arthritis (RA) has not been clarified. The present study aims to determine the antiangiogenic activity of EMS in collagen-induced arthritis (CIA) mice and in various angiogenesis models. Our data showed that EMS $(5 \mathrm{~g} / \mathrm{kg})$ markedly reduced the immature blood vessels in synovial membrane tissues of inflamed joints from CIA mice. It also inhibited vascular endothelial growth factor (VEGF)-induced microvessel sprout formation ex vivo. Meanwhile, EMS suppressed VEGF-induced migration, invasion, adhesion, and tube formation of human umbilical vein endothelial cells (HUVECs). Moreover, EMS significantly reduced the expression of angiogenic activators including interleukin (IL)-1 $\beta$, IL-6, and tumor necrosis factor-alpha (TNF- $\alpha$ ) in synovium of CIA mice. More interestingly, EMS blocked the autophosphorylation of VEGF-induced JAK1, STAT1, and STAT6 in CIA mice and VEGF-induced HUVECs. These findings suggest for the first time that EMS possesses the antiangiogenic effect in RA in vivo, ex vivo, and in vitro by interrupting the targeting of JAK/STAT activation.

\section{Introduction}

Rheumatoid arthritis (RA) is a progressive, systemic, and autoimmune disease characterized by synovial inflammation, hyperplasia, pannus formation, and cartilage and bone destruction [1-3], with the incidence in men and women rising steeply with age over 45 years [4], which seriously compromises human health. Pannus is the major reason and basic pathology in RA causing joint destruction, and angiogenesis is a key factor in generating and maintaining pannus [5]. Angiogenesis, the formation of new capillaries from preexisting vasculature, plays a critical role in the pathology of RA [6]. Approaches that target angiogenesis are part of a promising new era in the treatment of several conditions characterized by pathological angiogenesis, most importantly tumor growth in cancer and chronic inflammatory diseases such as RA [7]. Therefore, finding an effective method to inhibit angiogenesis can become an effective treatment for RA.

Angiogenesis is a complex process that is regulated by angiogenic mediators, including growth factors, primarily vascular endothelial growth factor (VEGF), and hypoxiainducible factors (HIFs), as well as proinflammatory cytokines, proteases, and others [6]. Among them, VEGF is the key regulator of angiogenesis and has been implicated in various biological activities, such as stimulating endothelial cell proliferation, migration, and formation of blood vessels [8]. The Janus kinases (JAKs) are part of an important signaling pathway that influences cellular responses to inflammation. JAK1 is a member of the JAKs family, which constitutes multiple signal transduction pathways with multiple members of the family of the STATs. JAK is 
activated by JAK1/STATs signaling pathways through the ligands and receptors on the surface of cells, inducing receptors dimerization and phosphorylation between each other. The generation development angiogenesis, invasion, and metastasis, and other links have taken part by activation of JAKs/STATs signaling pathways. Activation of JAKs/ STATs induces the angiogenesis by activating the transcription of various associated factors of angiogenesis such as VEGF.

$\mathrm{RA}$, as a common inflammatory disease of the immune system, belongs to the category of " $\mathrm{Bi}$ syndrome" in traditional Chinese medicine (TCM). TCM has long been used in treating RA. TCM has attracted much attention for its potential curative effect and few side effects. ErMiao San (EMS), formerly known as CangZhu San, was first seen in the book Effective Formulae Handed Down for Generations. In the Jin and Yuan Dynasties, the "Danxi Xinfa" has been renamed EMS for the first time. EMS is made up of two Chinese herbs, Cortex Phellodendri chinensis and Atractylodes lancea, and it has the function of eliminating heat and excreting dampness. It is commonly used in the treatment of RA, scrotal eczema, vaginitis, and others. The study found that EMS had anti-inflammatory activity by inhibiting tumor necrosis factor alpha (TNF- $\alpha$ ) [9] and interleukin (IL)$1 \beta$ [10]. Therefore, we investigated the antiangiogenic activity of EMS in collagen-induced arthritis (CIA) mice and in various angiogenesis models, and its possible mechanism of the action associated with VEGF-induced JAK/STAT-mediated signaling pathway was also explored.

\section{Materials and Methods}

2.1. Media, Reagents, and Antibodies. EMS was composed of $15 \mathrm{~g}$ of Cortex Phellodendri chinensis and $15 \mathrm{~g}$ of Atractylodes lancea. All the herbs used in this study were purchased from Beijing Tongrentang (Beijing, China). High-Dulbecco's Modified Eagle Medium (H-DMEM) and fetal bovine serum were got from Gibco (Rockville, MD, USA). Cycad blue (MTT) was the product of Sigma (USA). A mixture of lysis buffer, protease inhibitor, and protein phosphatase inhibitor and hypersensitive luminescent solution were obtained from Beijing Puli Lai Gene Technology Co. Ltd (Beijing, China). Matrigel was purchased from Corning (Corning, New York, USA). Bradford protein concentration assay kit and SDSPAGE protein buffer $(5 \mathrm{x})$ are from Biyun Tian biotechnology (Shanghai, China). Transwell chamber is from Costar (USA). Recombinant Human/Rat VEGF was bought from PeproTech (Rocky Hill, NJ, USA). Adhesion protein and horseradish enzyme labelled Goat anti-rabbit were purchased from Millipore (Billica, Ma, USA). Dimethyl sulfoxide (DMSO) was the product of Amresco (Hollywood, USA). Antifluorescence quenching coating agent was bought from Southern Biotech (Birmingham, USA). DAPI was purchased from AAT Bioquest company (USA). Crystal violet, SDS, glycine, and Tris alkali powder are purchased from the meimen Lun Biotechnology Co., Ltd. (Dalian, China). Bovine type II collagen, complete Freund's adjuvant (CFA), and incomplete Freund's adjuvant (IFA) were purchased from Chondrex (Redmond, WA, USA). Mouse
IL- $1 \beta$, mouse IL- 6 , and mouse TNF- $\alpha$ enzyme-linked immunosorbent assay (ELISA) kit were got from ABclonal (Boston, USA). Phosphorylated (p-) JAK1 antibody was bought from Cell Signaling Technology (Danvers, MA, USA); p-STAT6 antibody was purchased from LifeSpan Biological Sciences (California, USA); p-STAT1 antibody, JAK1 antibody, anti-STAT1, anti-STAT6, and anti-GAPDH antibodies were purchased from Abcam Company (Cambridge, UK).

2.2. Animals. Six-to-eight-week-old DBA/1 mice were obtained from Shanghai SLAC Laboratory Animal Co. Ltd (production license No: SCXK 2017-0005). And $130 \mathrm{~g}$ to $150 \mathrm{~g}$ SD rats (for rat aortic ring assay) were obtained from Guangdong Medical Laboratory Animal Center (production license No: SCXK 2018-0002). All the experimental protocols were approved by the Research Ethics Committee of Shenzhen Peking University-The Hong Kong University of Science and Technology Medical Center, in accordance with the National Institutes of Health Guidelines for the Care and Use of Laboratory Animals. All animals were treated in accordance with the guidelines and regulations for the use and care of animals of the Center for Laboratory Animal Care, Shenzhen Peking University-The Hong Kong University of Science and Technology Medical Center.

2.3. Preparation of EMS. An extract of EMS was prepared by decocting the dried prescription of herbs $(15 \mathrm{~g}$ of Cortex Phellodendri chinensis and $15 \mathrm{~g}$ of Atractylodes lancea) with boiling water for $1 \mathrm{~h}$ and extracted three times. The obtained suspension was separated by filtration and condensed to the concentration of $1.0 \mathrm{~g} / \mathrm{mL}$ solution and then stored at $4^{\circ} \mathrm{C}$ before administration. EMS was given to mice at $5 \mathrm{~g} / \mathrm{kg} / \mathrm{d}$.

2.4. Induction and Evaluation of CIA. We followed the methods of Liu et al. [11]. Eighteen male DBA/1 mice were randomly divided separately into 3 groups of equal numbers $(n=6)$ : the normal control group (Control), the CIA group (CIA), and CIA mice treated with EMS at $5 \mathrm{~g} / \mathrm{kg}$ dosage. Except the control group, all other mice were intradermally injected with $100 \mu \mathrm{g}$ bovine type II collagen in $0.05 \mathrm{M}$ acetic acid emulsified in complete Freund's adjuvant (CFA) at the base of the tail to induce arthritis. On day 21, mice were boosted intraperitoneally with $100 \mu \mathrm{g}$ type II collagen in incomplete Freund's adjuvant (IFA). Mice were observed once every 1-2 days after primary immunization. Arthritis severity was evaluated by arthritis scoring, which was performed by two independent, blinded observers. All 4 limbs of the mice were evaluated according to a visual assessment of inflammation or swelling and scored from 0 to 4 . To determine the disease severity, macroscopic scale ranging from 0 to 4 was used per paw, where $0=$ normal, $1=$ detectable arthritis with erythema, $2=$ substantial swelling and redness, $3=$ severe swelling and redness from joint to digit, and $4=$ maximal swelling and deformity with ankylosis. The disease score was expressed as a cumulative value for all paws, with a maximum possible score of 16 per 
mouse. This resulted in a maximum possible score of 4 per limb. The arthritis score was the total of the scores for all 4 limbs (maximum possible arthritis score 16). Arthritis incidence values are the number of positives/total number in group.

2.5. Treatment of CIA with EMS. Daily EMS $(5 \mathrm{~g} / \mathrm{kg})$ treatment was started from day 21 to day 40 after the first immunization. The treatment lasted for 20 days with a frequency of once a day. The agents were orally administered in a volume of $10 \mathrm{~mL} / \mathrm{kg}$. The mice in the control and CIA groups were administered with the same volume of saline.

2.6. Histology and Histologic Scoring. Mice were sacrificed by cervical dislocation on day 40 after the first immunization. Both hind knees were dissected and prepared into sections for staining with hematoxylin and eosin (H\&E). All sections were randomized and evaluated by two trained observers. Minor differences between observers were resolved by mutual agreement. The data was expressed as mean synovial vascularity (angiogenesis). The score was based on a scale of $0-3$, as previously described [11].

2.7. Histochemical and Immunohistochemical Analysis. This assay was carried out as previously described [12]. In order to measure blood vessel in synovial membrane tissues of inflamed joints, the polyclonal antibody (rat antibody, dilution 1:50, Abcam, Cambridge, MA, USA) recognizing the CD31 panendothelial antigen was used for microvessel and single endothelial cell staining on $5 \mu \mathrm{m}$ thick paraffin embedded sections of knee joints by immunohistochemical analysis as previously described [11]. For CD31 and alpha smooth muscle actin ( $\alpha$ SMA, dilution $1: 300$ ) immunofluorescence studies, the sections were incubated overnight in $4^{\circ} \mathrm{C}$. Then the sections were incubated for $1 \mathrm{~h}$ at room temperature with goat anti-rat secondary antibody (dilution $1: 400$ ) and goat anti-rabbit secondary antibody (dilution $1: 400)$. The results are expressed as the mean region of interest, representing the percentage of area covered with positively stained cells per image at a magnification of 400x. The vessels were determined using Pro-Plus Image 7 after dual staining for CD31 and $\alpha$ SMA.

Paraffin sections of joints were mounted on poly-L-lysine-coated slides. The paraffin sections were dewaxed by routine method and incubated for $10 \mathrm{~min}$ with $3 \% \mathrm{H}_{2} \mathrm{O}_{2}$. The sections were placed in a $37^{\circ} \mathrm{C}, 0.1 \%$ trypsinase for 5 $30 \mathrm{~min}$ for antigen retrieval. Each section was incubated with normal goat serum for $20 \mathrm{~min}$ at room temperature, and then with primary antibody VEGF (dilution $1: 50$ ), CD31 (dilution $1: 50$ ) overnight at $4^{\circ} \mathrm{C}$. After incubation with Polymer Helper for $20 \mathrm{~min}$ at $37^{\circ} \mathrm{C}$, sections reacted with poly-HRP anti-rabbit IgG for $20 \mathrm{~min}$ at $37^{\circ} \mathrm{C}$. The sections were then stained with 3,3-diaminobenzidine and counterstained with hematoxylin. Specimens were examined using a Leica image analyzer and analyzed by computer image analysis (Leica Microsystem Wetzlar Gmbh., Wetzlar, Germany) in a blinded manner. To localize and identify areas with positively stained cells, 10 random digital images per specimen of the synovial membrane tissues were recorded, and quantitative analysis was performed according to the color cell separation. The results are expressed as the mean region of interest, representing the percentage of area covered with positively stained cells per image at a magnification of 400x.

2.8. Ex Vivo Rat Aortic Ring Assay. This assay was performed as previously described [12]. Forty-eight well plates were covered by $100 \mu \mathrm{l}$ of matrigel $(5 \mathrm{mg} / \mathrm{mL})$ and left to polymerize for $45 \mathrm{~min}$ at $37^{\circ} \mathrm{C}$. Aortic rings were prepared from SD rats. Aortas were sectioned into sections $1-1.5 \mathrm{~mm}$ long, rinsed several times with PBS, placed on matrigel in wells, and covered with an additional $50 \mu \mathrm{l}$ of matrigel for $45 \mathrm{~min}$. The rings were cultured in $1 \mathrm{~mL}$ of $\mathrm{H}$-DMEM medium with $10 \%$ fetal bovine serum (FBS) with or without VEGF $(20 \mathrm{ng} / \mathrm{mL})$ plus various concentrations of EMS (0.2, 0.4 , and $0.8 \mathrm{mg} / \mathrm{mL}$ ). The medium was changed every 3 days. After 9 days of incubation, the rings were fixed with $4 \%$ paraformaldehyde. The microvessel growth was photographed using phase contrast microscopy. Numbers and lengths of the vascular branches in aortic ring were measured in Pro-Plus Image 7. All experiments were done in triplicate.

2.9. Cell Culture. We followed the methods of Liu et al. [11], and they were carried out described as previously described [12]. Human umbilical vein endothelial cells (HUVECs) were purchased from ScienCell Inc. (Carlsbad, CA, USA). The cells were cultured in sterile H-DMEM supplemented with $10 \% \mathrm{FBS}, 100 \mathrm{U} / \mathrm{mL}$ penicillin, and $80 \mathrm{U} / \mathrm{mL}$ streptomycin and were maintained at $37^{\circ} \mathrm{C}$ in a humidified $5 \% \mathrm{CO}_{2}$ incubator. HUVECs were used at passage numbers 4 to 6 in this study.

2.10. Cell Viability Assay. We followed the methods of Liu et al. [11], and they were carried out as previously described [12]. HUVECs $\left(5 \times 10^{4}\right.$ cells $\left./ \mathrm{mL}\right)$ were seeded in 96-well plates and incubated in sterile H-DMEM supplemented with $5 \% \mathrm{FBS}, 100 \mathrm{U} / \mathrm{mL}$ penicillin, and $80 \mathrm{U} / \mathrm{mL}$ streptomycin for $24 \mathrm{~h}$. Cells were then incubated with or without VEGF $(20 \mathrm{ng} / \mathrm{mL})$ and $1 \mathrm{~h}$ later with different concentrations of EMS $(0.2,0.4$, and $0.8 \mathrm{mg} / \mathrm{mL})$ for $24 \mathrm{~h}$. Cell viability was determined by MTT method according to the manufacturer's instructions. The experiments were carried out 3 times in triplicate measurements.

2.11. Scratch Healing Assay. We followed the methods of Liu et al. [11], and they were carried out as previously described [12]. HUVECs were seeded in a 48-well plate $\left(5 \times 10^{4}\right.$ cells per well). Cells were incubated overnight yielding confluent monolayers for wounding. Wounds were made using a pipette tip and photographs were taken immediately (time zero). After washing with PBS, $100 \mu \mathrm{l}$ of sterile H-DMEM medium (supplemented with 5\% FBS, $100 \mathrm{U} / \mathrm{mL}$ penicillin, and $80 \mathrm{U} / \mathrm{mL}$ streptomycin), with or 
without VEGF $(20 \mathrm{ng} / \mathrm{mL}$ ), and with or without different concentrations of EMS $(0.2,0.4$, and $0.8 \mathrm{mg} / \mathrm{mL})$, was added to the wells. $12 \mathrm{~h}$ later, photographs were taken again. The distance migrated by the cell monolayer to close the wounded area during this time was measured. Results were expressed as a migration index, that is, the distance migrated by EMS-treated relative to the distance migrated by control cells. Experiments were carried out in triplicate and repeated at least three times.

2.12. Transwell Migration Assay. We followed the methods of Liu et al. [11], and they were carried out as previously described [12]. The transwell migration assay was performed using a transwell chamber. HUVECs were seeded in the upper chambers $\left(5 \times 10^{4}\right.$ cells $/ \mathrm{mL}, 200 \mu \mathrm{l} /$ well $)$ of H-DMEM media containing EMS $(0.2,0.4$ and $0.8 \mathrm{mg} / \mathrm{mL})$. The bottom chamber of the apparatus contained $600 \mu \mathrm{l}$ of culture medium with or without VEGF ( $20 \mathrm{ng} / \mathrm{mL}$ for HUVECs). The chamber was incubated at $37^{\circ} \mathrm{C}$ for $6 \mathrm{~h}$. Nonmigrating cells in the upper chamber were carefully removed with cotton swabs, and cells on the lower surface of the membrane were fixed with $4 \%$ paraformaldehyde and stained with crystal violet solution. The total numbers of migrated cells were then counted in five randomly selected fields for each insert (magnification $\times 400$ ) using optical microscopy. All experiments were done in triplicate.

2.13. Cell Invasion Assay. We followed the methods of Liu et al. [11], and they were carried out as previously described [12]. The upper surfaces of the transwell inserts were precoated with Matrigel $(1.25 \mathrm{mg} / \mathrm{mL}, 20 \mu \mathrm{l} /$ well $)$ for $45 \mathrm{~min}$ at $37^{\circ} \mathrm{C}$. The bottom chamber of the apparatus contained $600 \mu \mathrm{l}$ of culture medium with or without VEGF $(20 \mathrm{ng} / \mathrm{mL}$ for HUVECs). HUVECs $\left(1 \times 10^{4}\right.$ cells/well $)$ were added to the upper chamber and incubated in normal growth medium with or without various concentrations of EMS $(0.2,0.4$, and $0.8 \mathrm{mg} / \mathrm{mL}$ ). After $14 \mathrm{~h}$ of incubation at $37^{\circ} \mathrm{C}$ and $5 \% \mathrm{CO}_{2}$, noninvasive cells on the upper membrane surfaces were removed by wiping with cotton swabs. The cells were fixed and stained with crystal violet solution. Cell invasion was quantified by counting the cells on the lower surface under a phase contrast microscope at 400x magnification. The average number of migrating cells was counted in five random fields. Three independent assays were performed.

2.14. Cell Adhesion Assay. We followed the methods of Liu et al. [11], and they were carried out as previously described [12]. HUVECs $\left(5 \times 10^{4}\right.$ cells $\left./ \mathrm{mL}\right)$ were seeded in fibronectin (FN, $20 \mathrm{mg} / \mathrm{l}$ ) or bovine serum albumin $(10 \mathrm{mg} / \mathrm{mL}$, used as negative control) coated 96-well plates and, respectively, incubated in sterile H-DMEM medium (supplemented with $5 \%$ FBS, $100 \mathrm{U} / \mathrm{mL} 1$ penicillin, and $80 \mathrm{U} / \mathrm{mL} 1$ streptomycin) for $24 \mathrm{~h}$. Cells were then incubated with or without VEGF $(20 \mathrm{ng} / \mathrm{mL})$ plus different concentrations of EMS $(0.2$, 0.4 , and $0.8 \mathrm{mg} / \mathrm{mL}$ ) for $24 \mathrm{~h}$. After treatment, cells were washed twice with PBS and $200 \mu \mathrm{l}$ of sterile H-DMEM medium containing 5\% FBS and $10 \%(\mathrm{v} / \mathrm{v})$ MTT reagent added to the cells. Absorbances at $490 \mathrm{~nm}$ were measured using a microplate reader. Results were expressed as cell adhesiveness. All experiments were done in triplicate.

2.15. Tube Formation Assay. In order to examine the inhibitory effect of EMS on HUVECs tube formation. We followed the methods of Liu et al. [11], and they were carried out as previously described [12]. Matrigel $(10 \mathrm{mg} / \mathrm{mL})$ was plated in 48-well culture plates and allowed to polymerize at $37^{\circ} \mathrm{C}$ in $5 \% \mathrm{CO}_{2}$ humidified for $30 \mathrm{~min}$. HUVECs were removed from culture, trypsinised, and resuspended in sterile H-DMEM medium (supplemented with 10\% FBS, $100 \mathrm{U} / \mathrm{mL}$ penicillin, and $80 \mathrm{U} / \mathrm{mL}$ streptomycin). HUVECs $\left(6 \times 10^{4}\right.$ cells $\left./ \mathrm{mL}\right)$ were added to each chamber, followed by the addition of various concentrations of EMS $(0.2,0.4$, and $0.8 \mathrm{mg} / \mathrm{mL})$ with or without VEGF $(20 \mathrm{ng} / \mathrm{mL})$, then incubated for $6 \mathrm{~h}$ at $37^{\circ} \mathrm{C}$ in $5 \% \mathrm{CO}_{2}$. After incubation, the capillary-like tube formation of each well in the culture plates was photographed using phase contrast microscopy. Quantitation of the antiangiogenic activity of EMS on tube formation was by counting the number of branch points. All experiments were done in triplicate.

2.16. Enzyme-Linked Immunosorbent Assay (ELISA). Sera from normal control, CIA, and EMS-treated CIA mice were collected. The expression levels of TNF- $\alpha$, IL- $1 \beta$, and IL-6 in sera were detected by ELISA according to the manufacturer's protocol. All experiments were done in triplicate.

2.17. Western Blot Analysis. Synovium tissues of knee joints from mice were collected. HUVECs were pretreated with EMS for $2 \mathrm{~h}$ and subsequently stimulated with VEGF $(20 \mathrm{ng} / \mathrm{mL})$ for $15 \mathrm{~min}$. Briefly, total protein was extracted using lysis buffer. Cell lysates $(50 \mu \mathrm{g})$ were loaded and separated using $10 \%$ sodium dodecyl sulfate--polyacrylamide gel electrophoresis, and then blotted onto a polyvinylidene fluoride membrane. Membranes were blocked at room temperature for two hours and incubated overnight at $4^{\circ} \mathrm{C}$ with primary antibodies for JAK1 $(1: 1000)$, pJAK1 (1:500), STAT1 $(1: 500)$, p-STAT1 $(1: 500)$, STAT6 $(1: 200)$, p-STAT6 $(1: 200)$, and GAPDH $(1: 2500)$. Subsequently membranes were incubated for $2 \mathrm{~h}$ at room temperature with secondary antibodies conjugated to horseradish peroxidase. The expression of GAPDH was used as an internal standard. All experiments were performed three times.

2.18. Statistical Analysis. The SPSS version 11.0 software for Windows (SPSS Inc., IL, USA) was used for statistical analysis. Continuous variables were expressed as $\bar{X} \pm s$. Pathological scores were analyzed by nonparametric Kruskal-Wallis tests. Other data were analyzed using ANOVA followed by a post hoc test or Student's $t$-test. Differences were considered statistically significant when $P$ was less than 0.05 . 


\section{Results}

3.1. EMS Prevents Arthritis Progression and Decreases Disease Severity of Arthritis in CIA Mice. The CIA model in DBA/1 mice was used to investigate the effect of EMS on arthritis. Daily EMS treatment was started from day 21 to day 40 after the first immunization. Macroscopic evidence of arthritis such as erythema or swelling was marked in CIA mice of CIA group, while EMS significantly attenuated clinical symptoms of arthritis in CIA mice (Figure 1(a)). For arthritis incidence and arthritis clinical symptoms, the evidences of joint destruction by histopathological evaluation also showed EMS to be highly effective. Inflammation, pannus, cartilage damage, and bone erosion in the groups receiving EMS (5 g/kg) were markedly reduced (Figures 1(b) and 1(e)). As shown in Figures 1(c) and 1(d), EMS attenuated the increasing arthritis score and arthritis incidence from day 23 after first immunization in CIA mice. Taken together, these results indicate that systemic administration of EMS in mice suppresses the clinical and pathologic severity of CIA.

\subsection{EMS Inhibits Angiogenesis in Synovium Tissue of Joints in} CIA Mice. Angiogenesis has been considered a critical step in the progression of chronic arthritis, as well as an early determinant in the development of RA. To assess the potential mechanism through which EMS exerts its antiarthritic action, $H \& E$ staining was used to examine the presence of vascular structures. As shown in Figures 2(a) and 2(b), the extent of vascular formation was indeed inhibited by the dose of $5 \mathrm{~g} / \mathrm{kg}$ EMS, as the score of mean synovial vascularity inside the construct decreased compared with that of CIA group. CD31, a marker of blood vessels, was stained in synovium tissue of joints by immunohistochemistry. As shown in Figures 2(c) and 2(d), a significant amount of CD31 staining was present in synovium tissue of inflamed joints from model mice, and this was markedly attenuated in EMS-treated mice. In order to further elucidate the mechanism of EMS on angiogenesis in RA, the protein levels of angiogenic activators including VEGF were detected in joint synovia of mice by immunohistochemistry. EMS strongly reduced the VEGF expression in synovia of CIA mice (Figures 2(e) and 2(f)). In addition, EMS affected the morphology of the newly formed immature microvessel, identified by staining for CD31, which were not covered by $\alpha$ SMA-positive perivascular cells (Figures 2(g)-2(i)). Quantitative evaluation further revealed that doses of $5 \mathrm{~g} / \mathrm{kg}$ EMS significantly reduced the number of immature $\mathrm{CD}^{2} 1^{+} /$ $\alpha \mathrm{SMA}^{-}$vessels (Figure 1) but not mature $\mathrm{CD}^{+} 1^{+} / \alpha \mathrm{SMA}^{+}$ vessels and decreased the total number of blood vessels (Figures 2(i) and 2(j)) in synovium tissues of inflamed joints of CIA mice by immunofluorescence analysis. These results suggest that EMS has a potent antiangiogenic activity in vivo.

3.3. EMS Suppresses VEGF-Induced Microvessel Sprout Formation Ex Vivo. The aortic ring assay, an ex vivo assay, mimics several stages of angiogenesis, including endothelial cellular proliferation, migration, tube formation, microvessel branching, and perivascular recruitment. As shown in
Figures 3(a)-3(d), VEGF significantly triggered endothelial cell migration and microvessel sprouting, leading to the formation of a complex microvessel network emerging from the aortic rings and growing outward; by contrast, EMS inhibited microvessel sprouting in a dose-dependent manner, suggesting that EMS suppressed VEGF-induced microvessel sprout formation ex vivo.

3.4. EMS Inhibited the Migration, Invasion, Adhesion, and Tube Formation of HUVECs. In angiogenesis, ECs migrate in response to several chemotactic factors [13]. Therefore, we attempted to elucidate whether EMS affects VEGF-induced EC migration and chemotaxis. As shown in Figures 4(a) and 4(e), EMS suppressed VEGF-induced wounding migration of HUVECs. Moreover, EMS strongly inhibited the VEGFinduced chemotaxis of HUVECs, determined by using a transwell chamber (Figures 4(b) and 4(f)).

To determine the effect of EMS on endothelial cell invasion, transwell chamber (precoated with Matrigel) experiments were also performed. EMS dose-dependently reduced the number of invasive cells migrating to the underside of the filters in the tanswell chambers after VEGF stimulation (Figures $4(\mathrm{c})$ and $4(\mathrm{~g})$ ), indicating a potent inhibitory effect of EMS on VEGF-induced endothelial cell invasiveness. In addition, the inhibitory effect of EMS on cell adhesiveness of HUVECs was determined by adhesion assay. EMS at a concentration ranging from 0.2 to $0.8 \mathrm{mg} / \mathrm{mL}$ significantly suppressed the cell adhesiveness of HUVECs induced by VEGF (data not shown). Moreover, a tube formation assay, which mimics angiogenesis, was detected to explore the effect of EMS on HUVECs tube formation. Robust and complete tubular-like structures of HUVECs were formed in the presence of VEGF. EMS disrupted tube formation in a concentration-dependent manner compared to the VEGF-induced group (Figures 4(d) and 4(h)).

We also examined whether the above suppressive effect of EMS was due to its cytotoxicity. Confluent HUVECs were treated with EMS and/or VEGF for $24 \mathrm{~h}$, and cytotoxicity was monitored by MTT assay. Our results showed that EMS did not exert any cytotoxic effects on HUVECs for $24 \mathrm{~h}$ under the experimental conditions used in the present study (Figure 4(i)), suggesting that EMS specifically suppresses the above functions of HUVECs.

3.5. EMS Reduces the Expression Levels of Proangiogenic Mediators. In order to investigate the mechanisms by which EMS suppressed the angiogenesis in RA, we detected the protein expression levels of angiogenic activators including TNF- $\alpha$, IL- $1 \beta$, and IL- 6 in sera of mice by ELISA. EMS significantly inhibited the expression of IL- $1 \beta$ (Figure $5(\mathrm{a})$ ), IL-6 (Figure 5(b)), and TNF- $\alpha$ (Figure 5(c)) in sera of CIA mice.

Since activation of JAK/STAT pathway plays a critical role in RA, we explored whether EMS could also impair angiogenesis by inhibiting the activation of JAK/STAT signaling pathways. EMS has significantly decreased the levels of phosphorylation of JAK1(Figures 5(d) and 5(g)), STAT1 (Figures 5(e) and 5(h)), and STAT6 (Figures 5(f) 

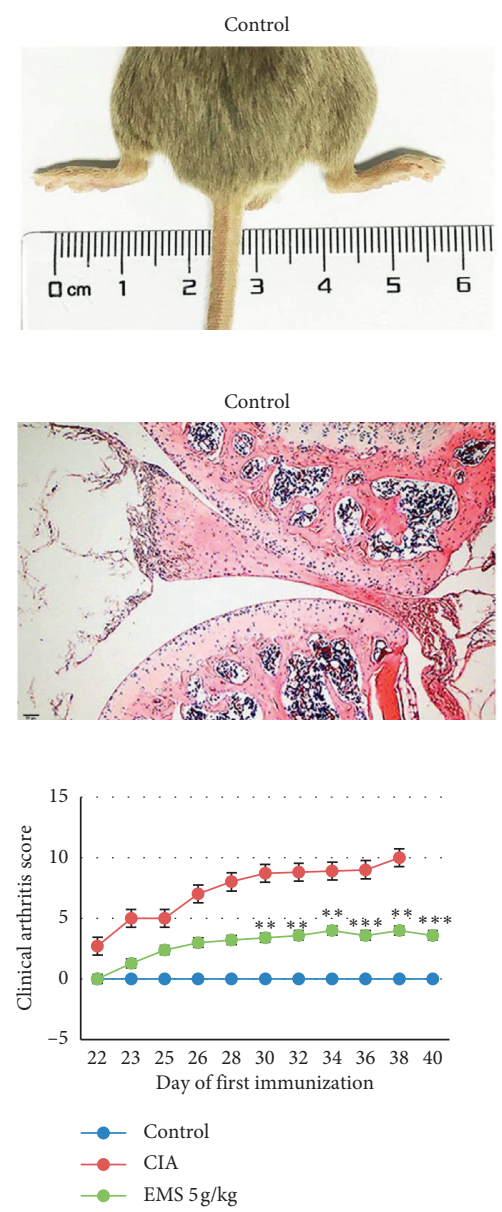

(c)

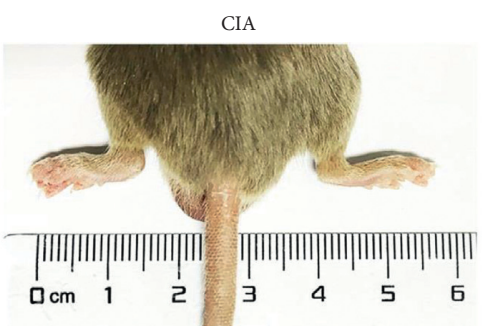

(a)

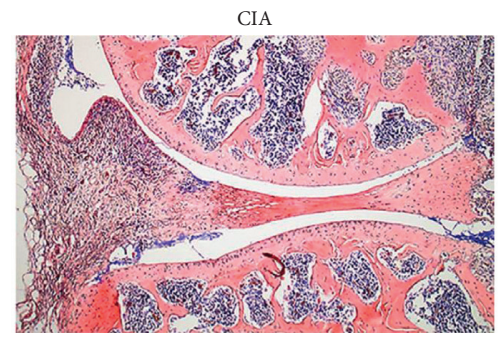

(b)

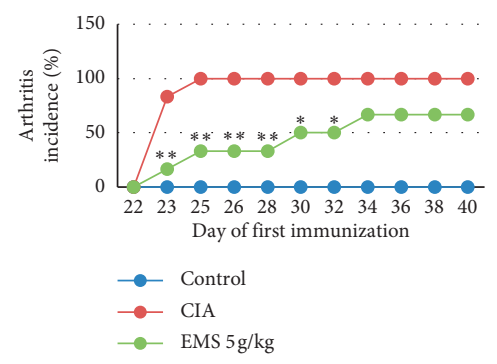

(d)
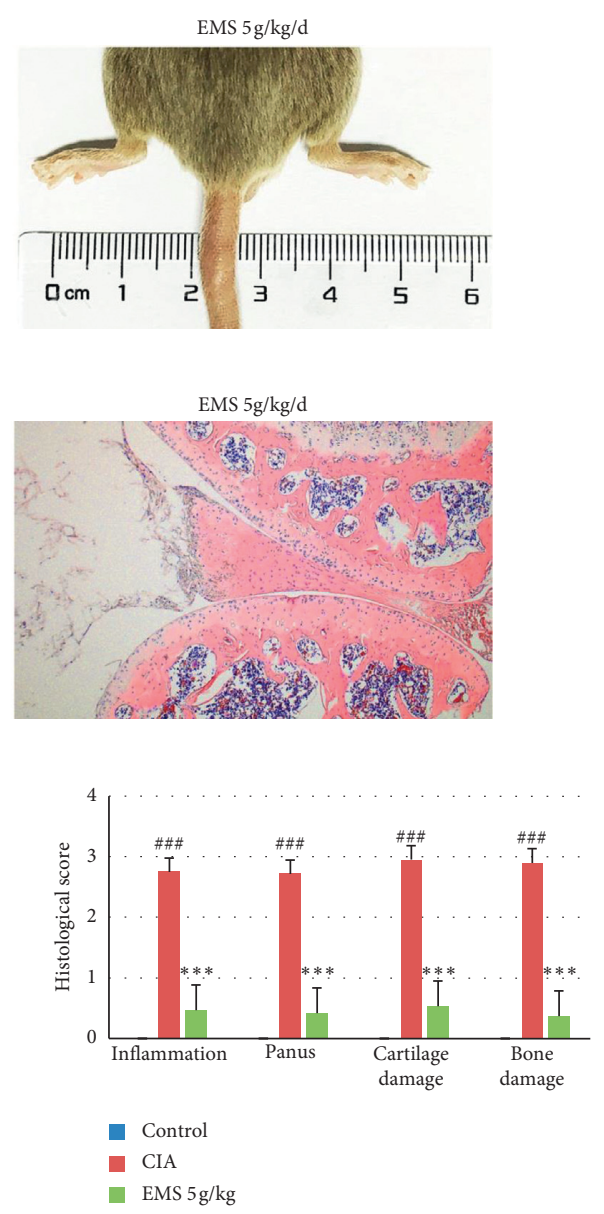

(e)

Figure 1: Therapeutic effects of EMS on collagen-induced arthritis (CIA) mice. CIA mice were orally administered EMS (5 g/kg/d), or vehicle for 20 days from the day of second immunization. (a) Macroscopic evidence of arthritis such as erythema or swelling was observed in mouse paws from each group. (b) Representative images of hematoxylin-eosin staining of ankle joint sections from each group. (c) Arthritis score was scored using a scale of 0-4 for each paw, with a maximum possible score of 16. (d) Arthritis incidence values are the number of positives/total number in each group. (e) The histological scores were evaluated and analyzed. The data are expressed as mean \pm SEM $(n=6)$. ${ }^{*} P<0.05,{ }^{* *} P<0.01,{ }^{* * *} P<0.001$, compared with the CIA group.

and 5(i)) in joint synovia of CIA mice and in VEGF-induced HUVECs, indicating that the inhibitory effect of EMS on JAK1, STAT1, and STAT6 phosphorylation is involved in the activation of JAK/STAT within the angiogenesis.

\section{Discussion}

Angiogenesis refers to the formation of new blood vessels from the development of existing capillaries or the posterior vein of capillaries, which plays an important role in the pathological process of RA. Previous reports indicate that EMS possesses anti-inflammatory activity. It is of great importance to understand its actions and potential drug targets in order to effectively use EMS for the therapy of RA. To further clarify the mechanisms of EMS acting on RA, we here discovered and demonstrated the antiangiogenic effect of EMS in vivo, ex vivo, and in vitro.

Angiogenesis as a critical component of disease progression in RA involves the pannus formation and maintenances of the infiltration of synovial membrane. RA synovium contains a significant fraction of immature blood vessels [14]. Progression of the disease increases the presence and density of immature but not mature vessels and only immature vessels are depleted in response to antiTNF-a therapy $[14,15]$. In the study, our results indicated that the immature blood vessels but not mature vessels in synovial membrane tissues of arthritic joints of CIA mice treated with EMS were significantly inhibited. In addition, EMS demonstrated potent inhibitory effect on sprouting of microvessel from rat aorta. Therefore, these results indicate that EMS has potent antiangiogenic activity both in vivo and ex vivo.

New vessel formation (angiogenesis) involves multiple steps including endothelial cell migration, invasion, adhesiveness, tube assembly, and remodeling [16]. In this study, we systematically investigated the potential effects of EMS on these key processes of VEGF-induced endothelial cell. Therefore, these results indicate that EMS inhibits angiogenesis by inhibiting the key angiogenic processes in vitro. 

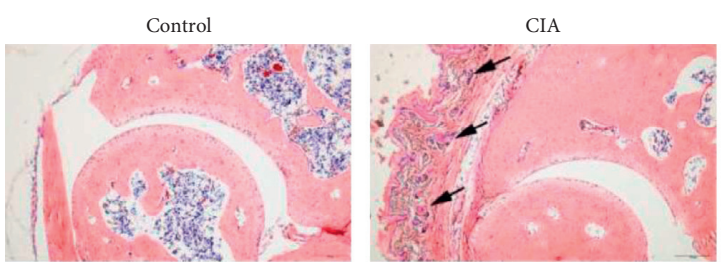

(a)
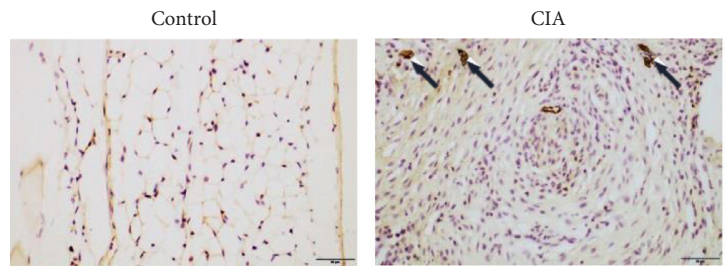

(c)
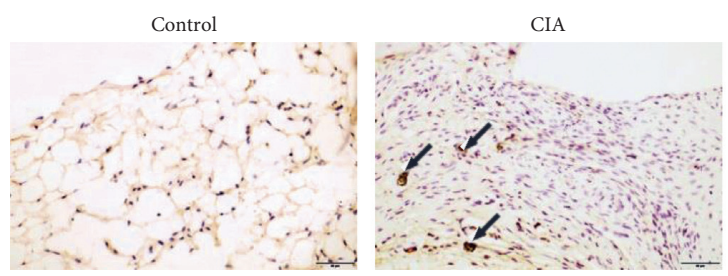

(e)
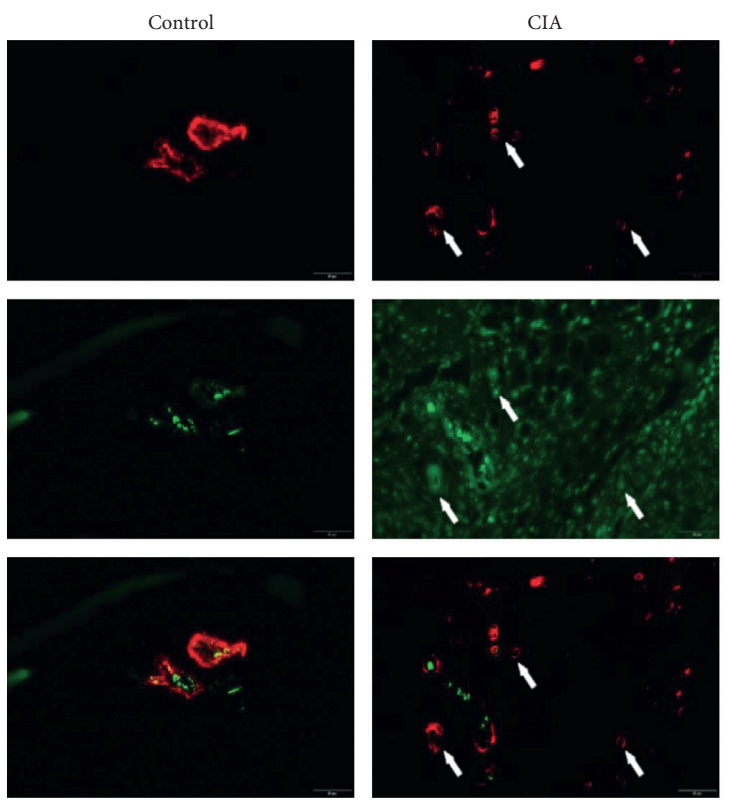

(g)
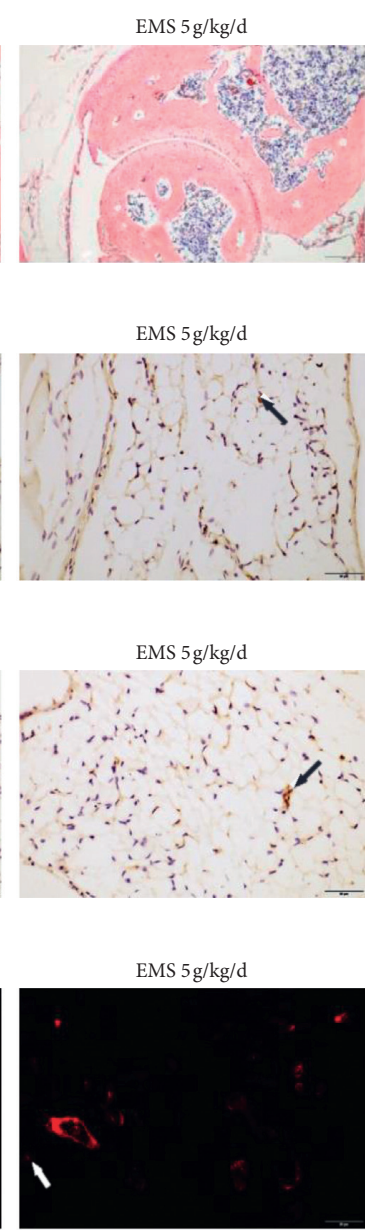

EMS $5 \mathrm{~g} / \mathrm{kg} / \mathrm{d}$

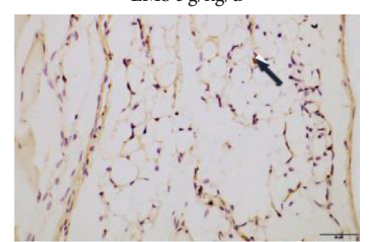

EMS $5 \mathrm{~g} / \mathrm{kg} / \mathrm{d}$
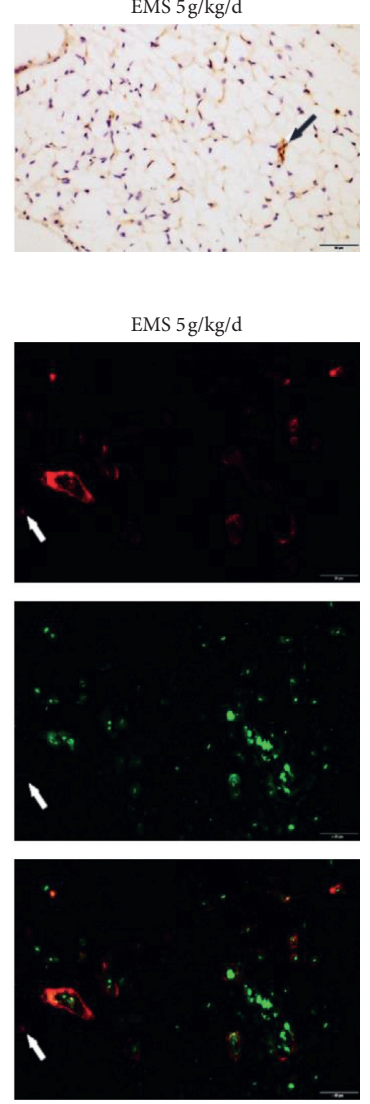

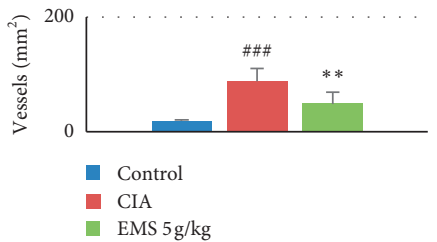

(b)

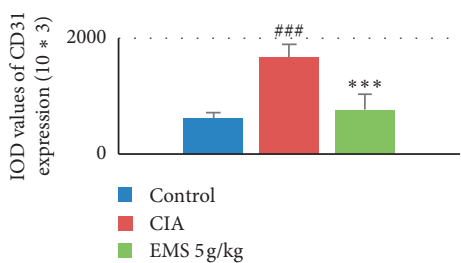

(d)

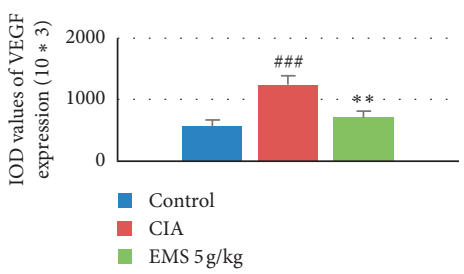

(f)

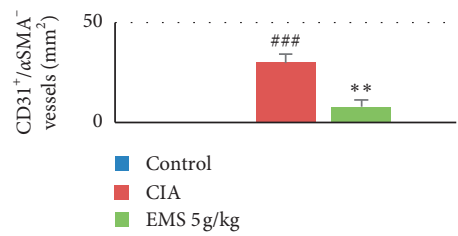

(h)

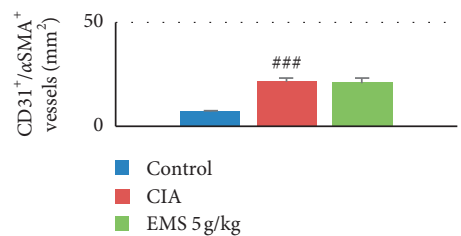

(i)

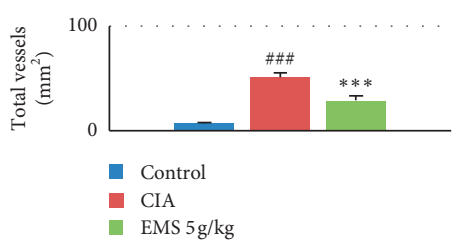

(j)

FIgURE 2: EMS decreases the vessel density in synovial membrane of inflamed joints in collagen-induced arthritis (CIA) mice. (a) Hematoxylin and eosin staining photomicrographs of synovial membrane tissues from knee joints of normal control, CIA, and EMS (5 g/kg) treated CIA mice, respectively. Black arrows indicate vascular structures. (b) Histological scores of vessel density from each group were analyzed. (c) CD31 immunohistochemical staining photomicrographs of synovial membrane tissues from knee joints of normal control, model CIA, and EMS (5 g/kg) treated CIA mice are shown, respectively. Black arrows indicate CD31-positive expression. (d) IOD values of CD31 expression by immunohistochemical analyses were measured by Image-Pro Plus 7 software. (e) Representative images of the localization of positive VEGF in synovial membrane tissues of knee joints from control, CIA, and EMS-treated mice, respectively. (f) Immunohistochemical analyses of VEGF-positive expression were measured. (g) Representative images of sections of joint synovial membrane tissues stained using Alexa 594-conjugated-anti-CD31 antibody (red) to label human endothelial colony forming cells-lined vessels and Alexa 488-conjugated anti- $\alpha \mathrm{SMA}$ antibody (green) to label perivascular cells. White arrows indicate $\mathrm{CD}^{+} / \alpha \mathrm{SMA}^{-} \mathrm{blood}$ microvessels. Immunofluorescence analyses of the numbers of $\mathrm{CD} 31^{+} / \alpha \mathrm{SMA}^{-}$immature vessels (h), $\mathrm{CD}_{3} 1^{+} / \alpha \mathrm{SMA}^{+}$mature vessels (i) and total vessels (j) in joint synovial membrane tissues. Data are represented as means \pm SEM $(n=6)$. \#\#\# $P<0.001$, compared to the control group; ${ }^{*} P<0.05,{ }^{* *} P<0.01$, and ${ }^{* * *} P<0.001$, compared to the CIA group. 

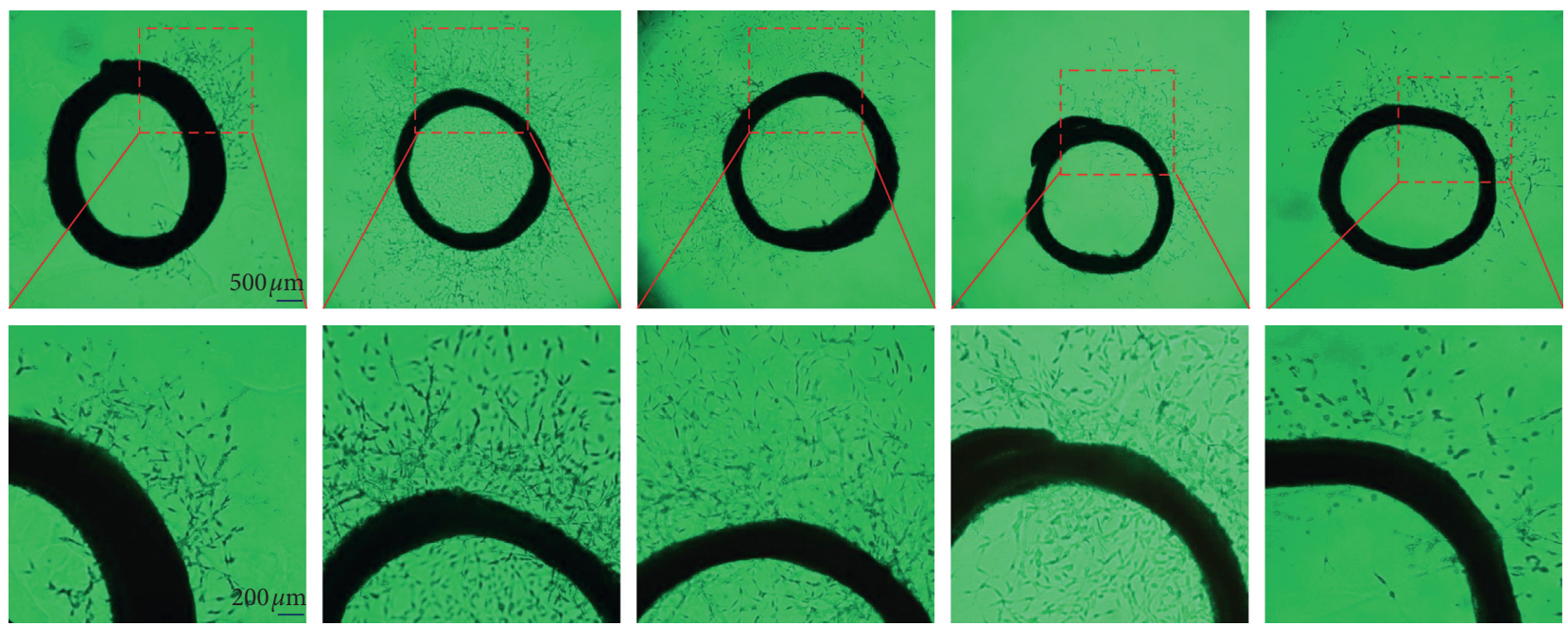

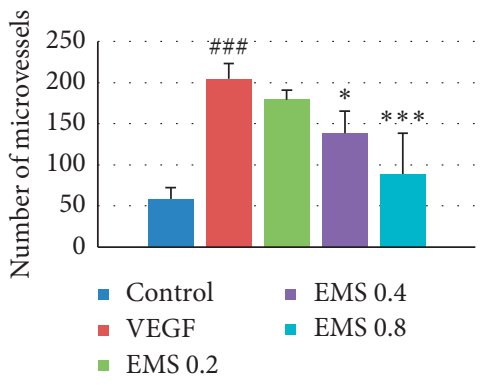

(b)

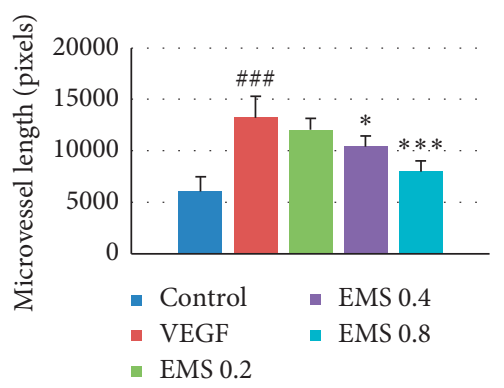

(c)

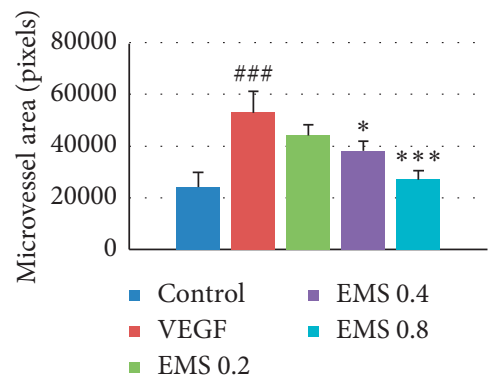

(d)

FIGURE 3: EMS suppresses VEGF 165 -induced vessel sprout formation ex vivo. Rat aortic rings were placed on a Matrigel drop in 48 -well plates for 9 days and covered with an additional drop of Matrigel. Serum-free H-DMEM medium ( $400 \mu \mathrm{l})$ with various concentrations of EMS ( 0.2 , 0.4 , and $0.8 \mathrm{mg} / \mathrm{mL})$ was added to each well. VEGF $(20 \mathrm{ng} / \mathrm{mL})$ was used as a positive control. Photographs of vessel sprout formation were obtained under an inverted microscope (magnification $\times 100$ ) (a). The number of microvessel vessels (b), microvessel length (c), and microvessel area (d) was counted, respectively. Three independent experiments were performed. Data are represented as means \pm SEM $(n=3)$. ${ }^{\# \# \#} P<0.001$, compared to the control group. ${ }^{*} P<0.05,{ }^{* *} P<0.01$, and ${ }^{* * *} P<0.001$, compared to the VEGF-treated group.
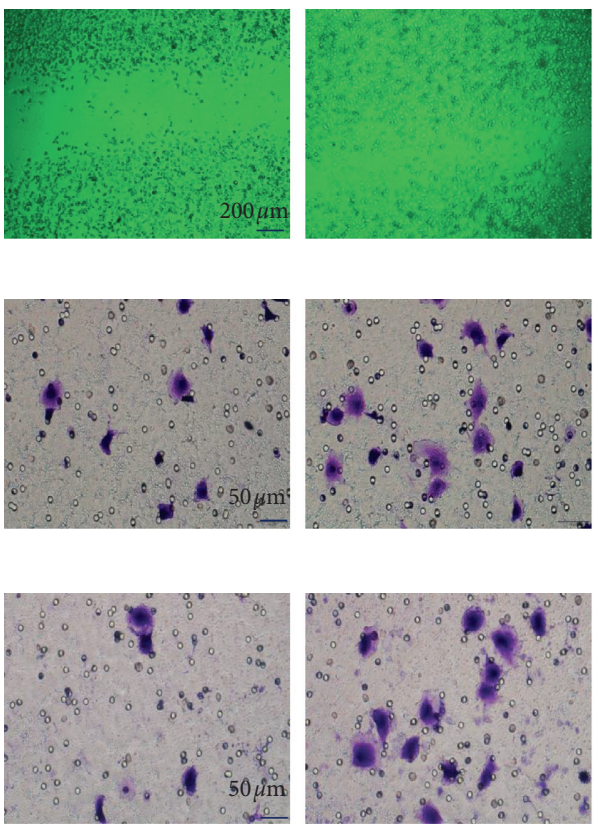

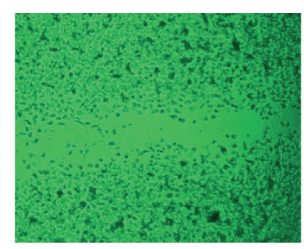

(a)
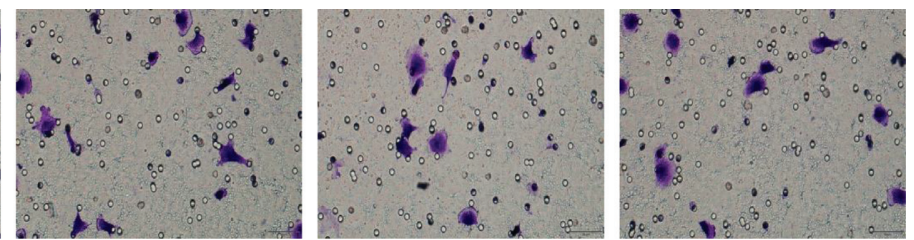

(b)
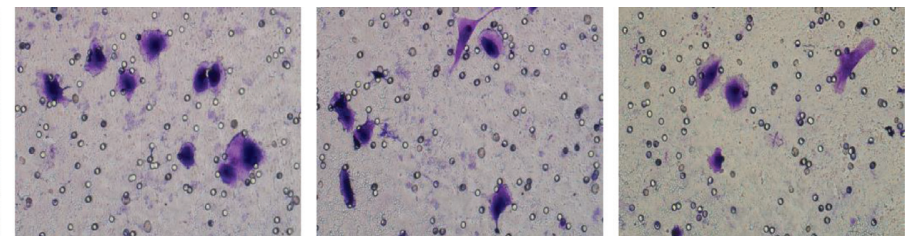

(c)

Figure 4: Continued. 

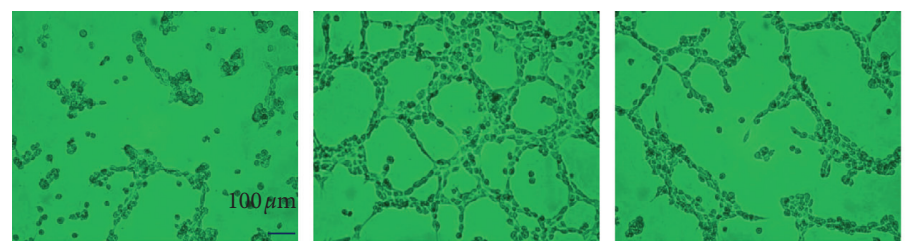

(d)

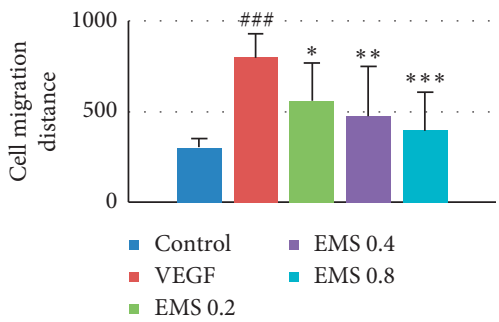

(e)

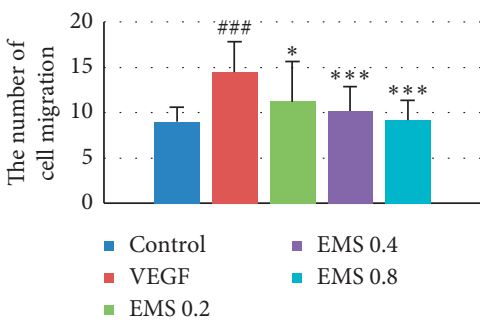

(f)
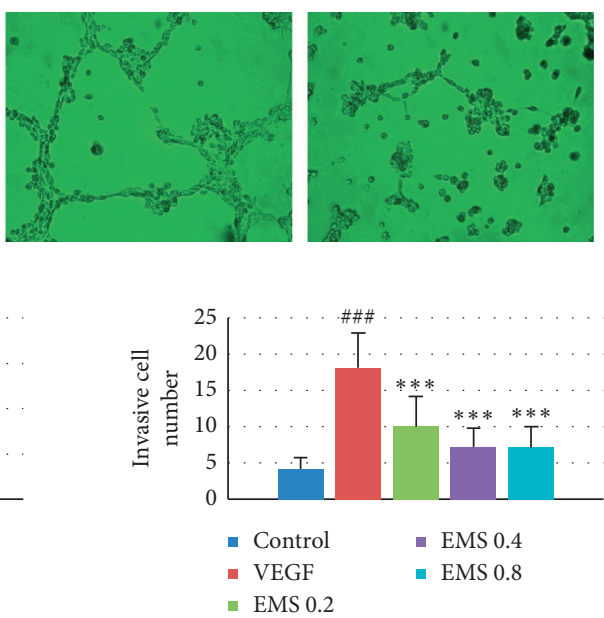

(g)

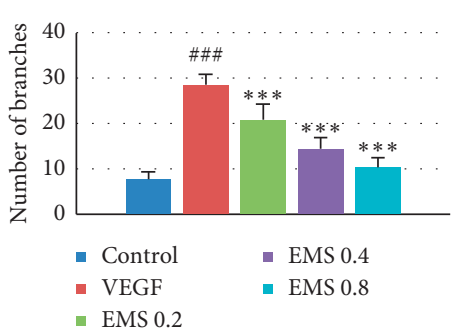

(h)

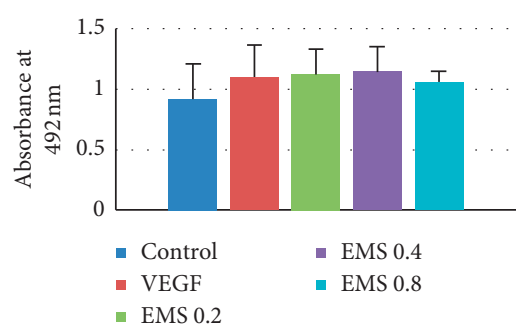

(i)

Figure 4: EMS inhibits VEGF-induced HUVECs migration, invasion, and tube formation. (a, e) HUVECs were placed in 48-well culture plates and wounded by scratching with pipette tips. Then they are allowed to migrate for $12 \mathrm{~h}$ in the presence of VEGF (20 ng/mL) with or without EMS $(0.2,0.4$, and $0.8 \mathrm{mg} / \mathrm{mL})$. The cell migration distance was calculated. $(\mathrm{b}, \mathrm{f})$ HUVECs were seeded in upper chamber with serum-free H-DMEM while VEGF were put in lower chamber with 10\%FBS H-DMEM. It is allowed to migrate for $6 \mathrm{~h}$ in the presence of EMS $(0.2,0.4$, and $0.8 \mathrm{mg} / \mathrm{mL}$ ) or not, then the migration cells were counted. (c, g) HUVECs were seeded in matrigel precoated upper chamber with serum-free H-DMEM. It is allowed to migrate for $14 \mathrm{~h}$ in the presence of VEGF $(20 \mathrm{ng} / \mathrm{mL})$ with or without EMS $(0.2,0.4$, and $0.8 \mathrm{mg} / \mathrm{mL}$ ), then the invasion numbers were counted. (d, h) HUVECs were plated on the matrigel precoated 48-well plates with or without the presence of VEGF $(20 \mathrm{ng} / \mathrm{mL})$ and/or EMS for $6 \mathrm{~h}$. Quantitation of the antiangiogenic activity of EMS on tube formation was by counting the number of branch points. (i) HUVECs were plated on the 96 -well plates with or without the presence of VEGF $(20 \mathrm{ng} / \mathrm{mL}) \mathrm{and} / \mathrm{or}$ EMS for $24 \mathrm{~h}$ and tested by MTT. All experiments were done in triplicate. Mean \pm SEM $(n=3)$ was calculated from independent experiments. ${ }^{\# \# \#} P<0.001$, compared to the control group; ${ }^{*} P<0.05$, ${ }^{* *} P<0.01$, and ${ }^{* * *} P<0.001$, compared to the VEGF-induced group.

Further investigation revealed that the antiangiogenic efficacy of EMS was shown to be mediated via interfering with the endothelial cell function.

A great number of proangiogenic factors, including VEGF, TNF- $\alpha$, IL- $1 \beta$, and IL- 6 , govern angiogenesis in RA [17]. Among these, VEGF is the most potent angiogenic regulator, which is produced in the synovium in response to proinflammatory cytokines such as TNF- $\alpha$ and IL- $1 \beta$. VEGF acts in angiogenesis via inducing EC proliferation, migration, and tube formation [18-21]. In the present study, to observe the mechanism of the antiangiogenic effect of EMS, these angiogenic mediators were investigated. Our results demonstrated that EMS significantly reduces the expression level of VEGF in synovium of CIA mice. Taken together, EMS inhibits angiogenesis by downregulating proangiogenic factors including VEGF, TNF- $\alpha$, IL- $1 \beta$, and IL-6.

JAK/STAT signaling pathway is an important multifunctional cytokine transduction pathway, which is involved in the regulation of various pathophysiological processes in vivo, such as cell proliferation and differentiation, immune regulation, inflammatory response, tumorigenesis, and development. Inflammatory factors can activate JAK kinase and promote STAT phosphorylation, which can cause inflammatory factor expression and cell injury, apoptosis, or proliferation. JAK and STAT1 were rarely expressed in synovium of OA patients or arthritis patients, but highly expressed in synovium of RA patients, and their expression decreased significantly after treatment [22]. STAT3 activation was only found in synovium of RA patients, but not in synovium of general arthritis patients [23]. De Hooge et al. [24] showed that granuloma formation and progressive arthritis could be seen in the yeast polysaccharide induced arthritis of STAT1 deficient mice, indicating that the antiinflammatory effect of STAT1 deficiency might be weakened. Thus, JAK/STAT pathway plays an important role in the pathogenesis of RA.

The JAK/STAT pathway is recognized as one of the major oncogenic signaling pathways activated in a variety of human malignancies [25]. STAT proteins not only play a crucial role in tumor cell proliferation, survival, and 


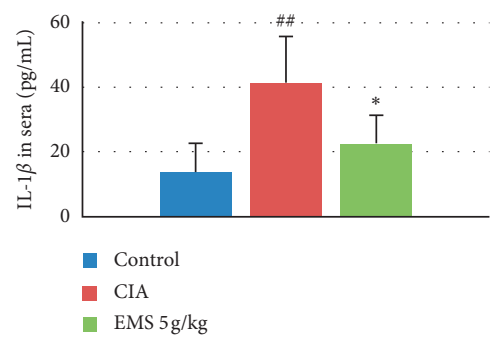

(a)

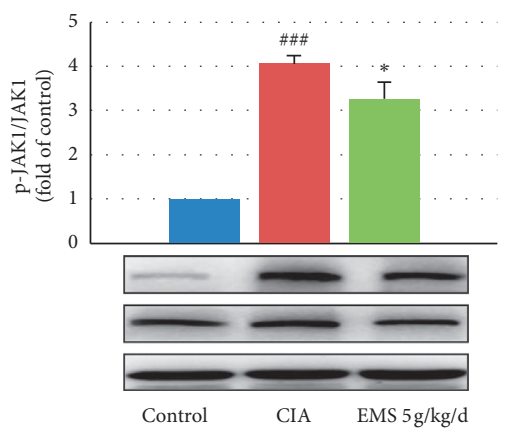

(d)

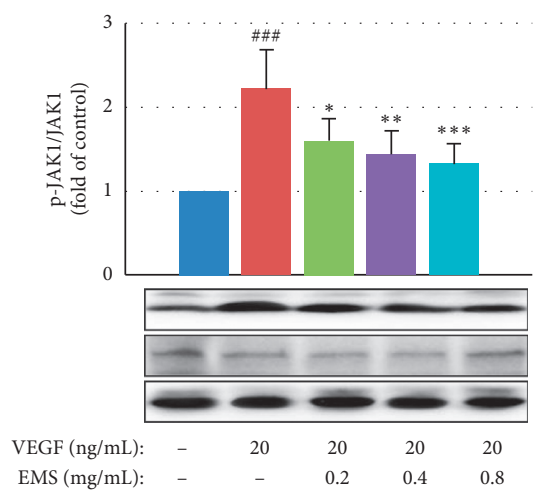

(g)

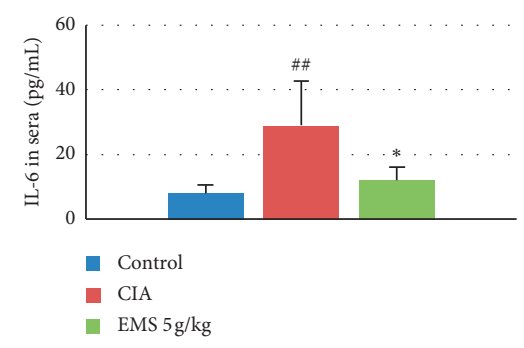

(b)

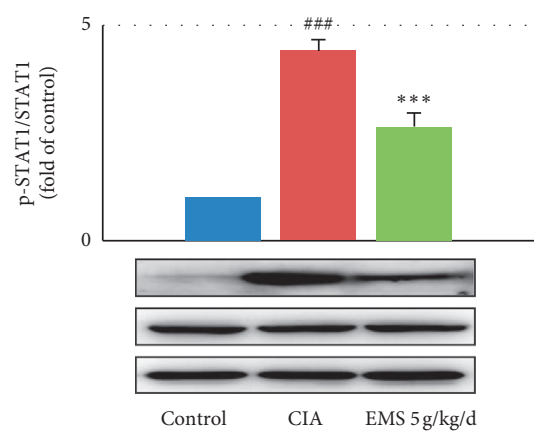

(e)

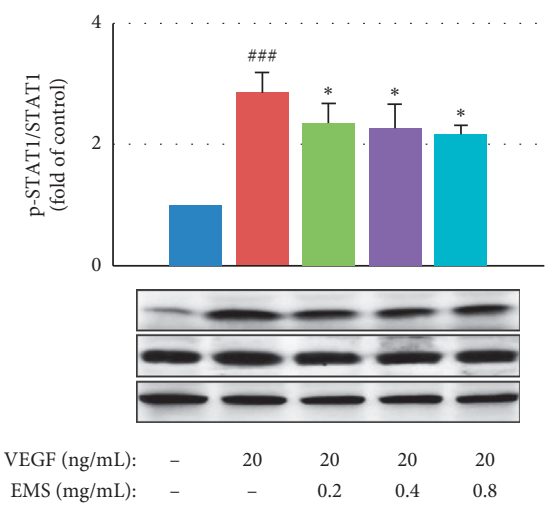

(h)

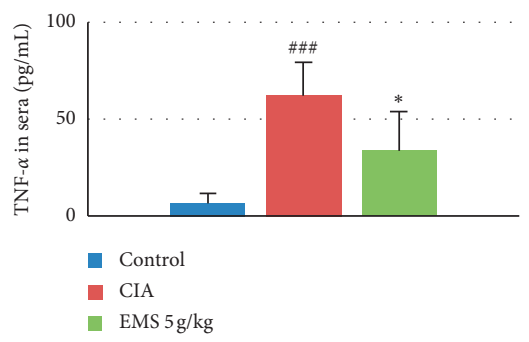

(c)

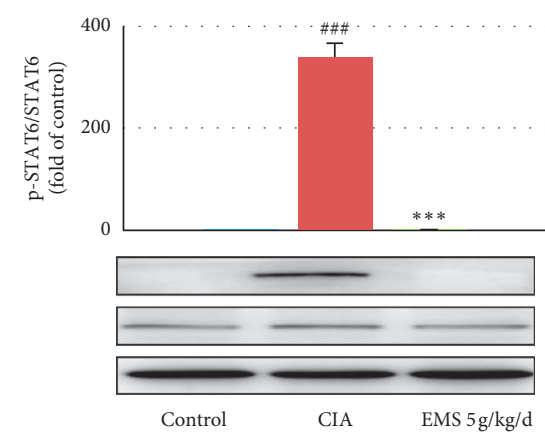

(f)

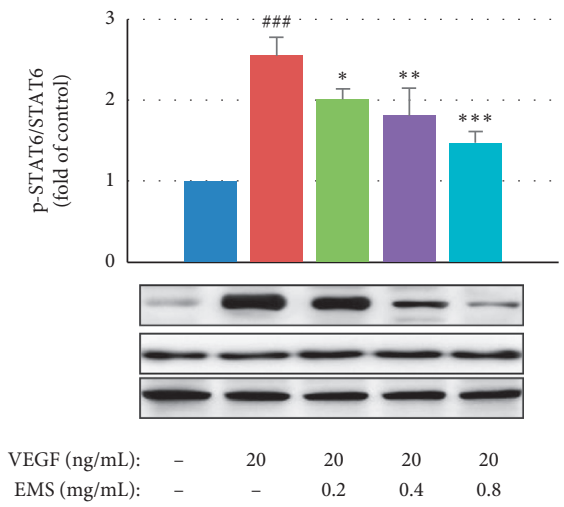

(i)

FIGURE 5: EMS reduces the expression levels of various proangiogenic activators in collagen-induced arthritis (CIA) mice and in HUVECs. CIA mice were orally administered EMS $(5 \mathrm{~g} / \mathrm{kg}$ ) for 20 days from the day of second immunization. The levels of IL- $1 \beta$ (a), IL-6 (b), and TNF- $\alpha$ (c) in sera of mice were measured by enzyme-linked immunosorbent assay (ELISA). The expression of phosphorylation of JAK1 (d), STAT1 (e), and STAT6 (f) in joint synovia of CIA mice was detected by Western blot. HUVECs were starved in $10 \%$ FBS medium for $48 \mathrm{~h}$ pretreated with EMS for $2 \mathrm{~h}$ and then stimulated with VEGF $(20 \mathrm{ng} / \mathrm{mL})$ for $15 \mathrm{~min}$ before collected. The levels of phosphorylation of JAK1 $(\mathrm{g})$, STAT1 (h), and STAT6 (i) were analyzed by Western blot, too. All experiments were done in triplicate. Mean \pm SEM $(n=3)$ was calculated from independent experiments. ${ }^{\# \#} P<0.01$, ${ }^{\# \#} P<0.001$, compared to the control group; ${ }^{*} P<0.05,{ }^{* *} P<0.01$, and ${ }^{* * *} P<0.001$, compared to the CIA/VEGF-induced group.

invasion, but also significantly contribute to the formation of a unique tumor microenvironment [26]. The incidence of RA is similar to tumor in many aspects. Furthermore, a link between STATs activation in endothelial cells and angiogenesis has been described in several studies [27-30].

To explore the molecular mechanism of the antiangiogenic effect of EMS, we assessed the ability of EMS on the expression and activation of JAK/STAT. Our data showed that EMS significantly blocked the kinase activity of JAK/STAT by downregulating VEGF-induced autophosphorylation of JAK1, STAT1, and STAT6 expression in CIA mice and HUVECs. These results suggest the inhibitory effect of EMS on angiogenesis by targeting JAK/STAT.
In conclusion, our results indicate that EMS significantly reduced synovial angiogenesis in CIA mice, inhibiting sprouting of microvessel in rat aorta. This reduction may be attributable to the inhibition of endothelial cell migration, adhesion, invasion, and tube formation. Furthermore, EMS exerts antiangiogenic effects by downregulating angiogenic activators and suppressing the JAK/STAT signaling pathway, which plays multiple roles in the regulation of angiogenesis. These findings suggest for the first time that EMS possesses the antiangiogenic effect in RA in vivo, ex vivo, and in vitro by interrupting the targeting of JAK/STAT activation. Therefore, EMS may act as a potential therapeutic agent for RA treatment through its antiangiogenic effects in the synovium. 


\section{Data Availability}

All data used to support the findings of this study are included within the article.

\section{Conflicts of Interest}

The authors declare that they have no conflicts of interest.

\section{Acknowledgments}

This work was supported by Shenzhen Science and Technology Program for Basic Research (Grants No. JCYJ20170307112009204), Traditional Chinese Medicine Bureau of Guangdong Province (Grants No. 20183011).

\section{References}

[1] S. Konisti, S. Kiriakidis, and E. M. Paleolog, "Hypoxia-a key regulator of angiogenesis and inflammation in rheumatoid arthritis," Nature Reviews Rheumatology, vol. 8, no. 3, pp. 153-162, 2012.

[2] X. You, D. L. Boyle, D. Hammaker, and G. S. Firestein, "PUMA-mediated apoptosis in fibroblast-like synoviocytes does not require p53," Arthritis Research \& Therapy, vol. 8, no. 6, p. R157, 2006.

[3] K. Farheen and S. K. Agarwal, "Assessment of disease activity and treatment outcomes in rheumatoid arthritis," Journal of Managed Care Pharmacy, vol. 17, no. 9, pp. S09-S13, 2011.

[4] D. P. M. Symmons, E. M. Barrett, C. R. Bankhead, D. G. L. Scott, and A. J. Silman, "The incidence of rheumatoid arthritis in the United Kingdom: results from the norfolk arthritis register," Rheumatology, vol. 33, no. 8, pp. 735-739, 1994.

[5] C. Hong, C. Shen, H. Ding et al., "An involvement of SR-B1 mediated p38 MAPK signaling pathway in serum amyloid A-induced angiogenesis in rheumatoid arthritis," Molecular Immunology, vol. 66, no. 2, pp. 340-345, 2015.

[6] N. Thairu, S. Kiriakidis, P. Dawson, and E. Paleolog, "Angiogenesis as a therapeutic target in arthritis in 2011: learning the lessons of the colorectal cancer experience," Angiogenesis, vol. 14, no. 3, pp. 223-234, 2011.

[7] S. W. Tas, C. X. Maracle, E. Balogh, and Z. Szekanecz, "Targeting of proangiogenic signalling pathways in chronic inflammation," Nature Reviews Rheumatology, vol. 12, no. 2, pp. 111-122, 2016.

[8] N. Ferrara and T. Davis-Smyth, "The biology of vascular endothelial growth factor," Endocrine Reviews, vol. 18, no. 1, pp. 4-25, 1997.

[9] G. Chen, K.-K. Li, C.-H. Fung et al., "Er-Miao-San, a traditional herbal formula containing rhizoma atractylodis and cortex phellodendri inhibits inflammatory mediators in LPSstimulated RAW264.7 macrophages through inhibition of NF- $\kappa \mathrm{B}$ pathway and MAPKs activation," Journal of Ethnopharmacology, vol. 154, no. 3, pp. 711-718, 2014.

[10] S. Bae, Y. Jung, Y. Choi, and S. Li, "Effects of Er-Miao-San extracts on TNF-alpha-induced MMP-1 expression in human dermal fibroblasts," Biological Research, vol. 48, no. 1, p. 8, 2015.

[11] C. Liu, X. Kong, X. Li et al., "Wen Luo Yin inhibits angiogenesis in collagen-induced arthritis rat model and in vitro," Journal of Ethnopharmacology, vol. 149, no. 2, pp. 478-489, 2013.
[12] L. He, C. Liu, C. Sun et al., "Wu-tou decoction inhibits angiogenesis in experimental arthritis by targeting VEGFR2 signaling pathway," Rejuvenation Research, vol. 21, no. 5, pp. 442-455, 2018.

[13] R. M. Strieter, P. J. Polverini, S. L. Kunkel et al., "The functional role of the ELR motif in CXC chemokine-mediated angiogenesis," Journal of Biological Chemistry, vol. 270, no. 45, pp. 27348-27357, 1995.

[14] E. Izquierdo, J. D. Cañete, R. Celis et al., "Immature blood vessels in rheumatoid synovium are selectively depleted in response to anti-TNF therapy," PLoS One, vol. 4, no. 12, Article ID e8131, 2009.

[15] A. Kennedy, C. T. Ng, T. C. Chang et al., "Tumor necrosis factor blocking therapy alters joint inflammation and hypoxia," Arthritis \& Rheumatism, vol. 63, no. 4, pp. 923-932, 2011.

[16] M. Potente, H. Gerhardt, and P. Carmeliet, "Basic and therapeutic aspects of angiogenesis," Cell, vol. 146, no. 6, pp. 873-887, 2011.

[17] H. A. Elshabrawy, Z. Chen, M. V. Volin, S. Ravella, S. Virupannavar, and S. Shahrara, "The pathogenic role of angiogenesis in rheumatoid arthritis," Angiogenesis, vol. 18, no. 4, pp. 433-448, 2015

[18] Z. Szekanecz, T. Besenyei, G. Paragh, and A. E. Koch, "New insights in synovial angiogenesis," Joint Bone Spine, vol. 77, no. 1, pp. 13-19, 2010.

[19] S. R. Pickens, M. V. Volin, A. M. Mandelin, J. K. Kolls, R. M. Pope, and S. Shahrara, "IL-17 contributes to angiogenesis in rheumatoid arthritis," The Journal of Immunology, vol. 184, no. 6, pp. 3233-3241, 2010.

[20] F. Guadagni, P. Ferroni, R. Palmirotta, I. Portarena, V. Formica, and M. Roselli, "TNF/VEGF cross-talk in chronic inflammation-related cancer initiation and progression: an early target in anticancer therapeutic strategy," In Vivo, vol. 21, no. 2, pp. 147-161, 2007.

[21] M. J. Bottomley, N. J. Webb, C. J. Watson, P. J. Holt, A. J. Freemont, and P. E. Brenchley, "Peripheral blood mononuclear cells from patients with rheumatoid arthritis spontaneously secrete vascular endothelial growth factor (VEGF): specific up-regulation by tumour necrosis factoralpha (TNF-alpha) in synovial fluid," Clinical and Experimental Immunology, vol. 117, no. 1, pp. 171-176, 1999.

[22] C. Monari, S. Bevilacqua, M. Piccioni et al., "A microbial polysaccharide reduces the severity of rheumatoid arthritis by influencing Th17 differentiation and proinflammatory cytokines production," The Journal of Immunology, vol. 183, no. 1, pp. 191-200, 2009.

[23] T. Shouda, T. Yoshida, T. Hanada et al., "Induction of the cytokine signal regulator SOCS3/CIS3 as a therapeutic strategy for treating inflammatory arthritis," Journal of Clinical Investigation, vol. 108, no. 12, pp. 1781-1788, 2001.

[24] A. S. K. De Hooge, F. A. J. van de Loo, M. I. Koenders et al., "Local activation of STAT-1 and STAT-3 in the inflamed synovium during zymosan-induced arthritis: exacerbation of joint inflammation in STAT-1 gene-knockout mice," Arthritis \& Rheumatism, vol. 50, no. 6, pp. 2014-2023, 2004.

[25] H. Yu and R. Jove, "The STATs of cancer - new molecular targets come of age," Nature Reviews Cancer, vol. 4, no. 2, pp. 97-105, 2004.

[26] H. Lee, A. Herrmann, J.-H. Deng et al., "Persistently activated Stat3 maintains constitutive NF- $\kappa \mathrm{B}$ activity in tumors," Cancer Cell, vol. 15, no. 4, pp. 283-293, 2009. 
[27] H. Yu, D. Pardoll, and R. Jove, "STATs in cancer inflammation and immunity: a leading role for STAT3," Nature Reviews Cancer, vol. 9, no. 11, pp. 798-809, 2009.

[28] M. Bartoli, D. Platt, T. Lemtalsi et al., "VEGF differentially activates STAT3 in microvascular endothelial cells," The FASEB Journal, vol. 17, no. 11, pp. 1562-1564, 2003.

[29] H. Leong, P. S. Mathur, and G. L. Greene, "Green tea catechins inhibit angiogenesis through suppression of STAT3 activation," Breast Cancer Research and Treatment, vol. 117, no. 3, pp. 505-515, 2009.

[30] Y. Dong, B. Lu, X. Zhang et al., "Cucurbitacin E, a tetracyclic triterpenes compound from Chinese medicine, inhibits tumor angiogenesis through VEGFR2-mediated Jak2-STAT3 signaling pathway," Carcinogenesis, vol. 31, no. 12, pp. 2097-2104, 2010. 